\title{
Obesity incidence is related to month of birth
}

\begin{abstract}
Serpil CECEN
Sports Physiology, Marmara University, Pendik Education and Research Hospital, Pendik, Istanbul, Turkey.
\end{abstract}

\author{
Corresponding Author: Serpil CECEN \\ E-mail: drserce@gmail.com
}

Submitted: 05.02.2020 Accepted: 10.05.2020

\begin{abstract}
Objective: The relationship between the month of birth and obesity status of individuals has been claimed but not proven convincingly. We aim to provide more evidence towards the presumed relationship between month of birth and physical characteristics of individuals.

Materials and Methods: We used a Bio-impedance device to determine physical characteristics of 3,000 informed volunteers who attended our clinic.

Results: We found that the individuals who were born in the first three months of the year were heavier, taller and older than the applicants who were born in later months of the year.

Conclusion: We can conclude that the month of birth was significantly related to obesity incidence. We believe that this information will add to the knowledge on the importance of the relationship between birth month and physical and health characteristics of individuals living in a country with extreme seasonal temperatures.

Keywords: Body mass index, Weight, Fat content, Season
\end{abstract}

\section{INTRODUCTION}

Month of birth has been claimed to be correlated with the prevalence and incidence of many diseases and disorders [1, 2]. Even physical characteristics and psychological parameters claimed to be related to the month of birth $[3,4]$. For example, a German group studied six million cardiovascular deaths between 1992 and 2007 and reported that deaths due to cardiovascular problems both in men and women were significantly less in individuals who were born in the month of May compared with the individuals who were born in other months of the year [5]. Benegas et al., investigated the effect of seasonal variation in mean systolic blood pressure in Spanish population and found that the greatest difference in systolic blood pressure occurred between adults born in spring $(134.1 \mathrm{mmHg})$ and those born in autumn $(140.3 \mathrm{mmHg})$ [6]. In another study by the same group, it was shown that male adults born in summer are $1.7 \mathrm{~cm}$ taller than their counterparts born in winter [3].

Around the globe, there are studies that used large data such as a Chinese study on 487,529 adults showing that the spring - and early summer-born adults have higher body mass index and waist circumference and shorter leg length than autumn - and winter-born adults [7]. Also, a UK study on 450,000 adults showed that season of birth is associated with birth weight, pubertal timing, adult body size and even educational attainment [4]. Similarly, a Japanese study used data from 69,693 children and showed that spring born children were taller and heavier than winter born children, but the prevalence of obesity did not vary with the season of birth [8]. A Polish study's finding on 1,241 children, though using a smaller sample than the Japanese study, found the opposite, i.e, children born in April to September were generally shorter and less heavy than those born in October to March [9]. A similar finding to the Polish study came from a South African study that investigated 1,165 adults and showed that individuals born in February to July were shorter and weighed less (by 13 to $17 \%$ of the standard deviation) than those born in August to January [10].

As briefly summarized above, many studies exist regarding the importance of the month of birth not only on the physical characteristics of individuals but also on the prevalence, 
incidence, and resistance to diseases and even on the success in schooling. However, the results of these studies do not exactly match. There may be confounding factors such as the hemispheric differences since when the Northern hemisphere is enjoying sunlight and heat in the months of May to September, the Southern hemisphere in the same time is going through winter. Despite this obvious difference in times of heat / sunlight, hemispheric differences for the cause of the above findings have been rejected by Henneberg and Louw on the grounds of finding similar effects of birth month on individuals living in the Southern and Northern hemispheres [11]. They have suggested that rather than the local heat / sunlight, a common factor for the entire globe, possibly related to the ellipsoid shape of the orbit of the planet, may be responsible [10].

Living in a country that enjoys extremes of temperature in seasons, we wished to examine the relationship between the months of births and obesity status of 3,000 individuals who attended our clinic.

\section{MATERIALS and METHODS}

This study was performed on outpatients who applied to our Sports Physiology clinic due to obesity from 2015 January to 2017 July. The study was approved by the Local Ethics Committee Three thousand subjects signed informed consent forms prepared by the human ethics committee. The heights of the subjects were measured while they were barefooted and back touching a wall. For each subject, we used a Bio-impedance device (Tanita BC418, Switzerland) to determine body weight, body mass index (BMI), fat percentage, fat weight and fat free mass (muscle weight). Mean and standard deviation of these values are shown in Table I. We have then formed a table to indicate the mean values of these variables against the month of birth (Table II).

\section{Statistical Analyses}

For each of the physical characteristics data we used Trendline analyses ( $4^{\text {th }}$ level Polynomial Trendline; Excel 2016). Trendline analysis is a linear least squares regression tool that can be employed to provide some correlation to data points that are seemingly not linked at all. Using this analysis tool, we built line of best fit graphs to illustrate concurrent effect of the month of birth on physical characteristics of individuals.

We have also used the z-test to see the dissipation between the average values of each month compared with the average value for the entire year for each of the variables. We used the following formula to obtain the z-value:

(Average value for one month - Average value for the year) / Standard Deviation value for the year

Significance level was set to $\mathrm{p}<0.05$. We further examined the $\mathrm{z}$-test values using a non-parametric test to illustrate the months of special importance for physical characteristics of individuals.

\section{RESULTS}

Examination of the 3,000 outpatients of our obesity clinic using Trend analysis we found significant relationships between the month of birth and age of the applicants; weight of the applicants; height of the applicants; BMI and fat free mass and fat mass values of the applicants. Age and month of birth, the height, the weight, fat weight, muscle weight, BMI, and fat percentage of the applicants are given in figures 1-7.

Table I. Descriptive characteristics of individuals

\begin{tabular}{|l|c|c|}
\hline & Mean & SD \\
\hline Age $($ year$)$ & 29.3 & 16.3 \\
\hline Height $(\mathrm{cm})$ & 157.5 & 22.6 \\
\hline Weight $(\mathrm{kg})$ & 89.7 & 109.2 \\
\hline BMI $\left(\mathrm{kg} / \mathrm{m}^{2}\right)$ & 35.2 & 21.6 \\
\hline \%Fat & 38.9 & 12.8 \\
\hline Fat weight $(\mathrm{kg})$ & 35 & 17.6 \\
\hline Muscle weight $(\mathrm{kg})$ & 51.8 & 17.7 \\
\hline
\end{tabular}

Table II. Z-test results for the entire data for 3,000 subjects. Z-value was obtained; for example for the distribution of height for the month of January as follows:

$Z=$ Average height value for January - Average height value for the entire year / Standard Deviation for height value for the entire year.

\begin{tabular}{|c|c|c|c|c|c|c|c|}
\hline & Age & Height & Weight & BMI & Fat $\%$ & $\begin{array}{c}\text { Fat } \\
\text { Weight }\end{array}$ & $\begin{array}{l}\text { Muscle } \\
\text { Weight }\end{array}$ \\
\hline January & $0.18^{\star}$ & $0.07^{\star *}$ & $0.1^{*}$ & $0.1^{\star}$ & $0^{*}$ & $0.12^{\star}$ & $0.07^{*}$ \\
\hline February & $0.18^{*}$ & $0.15^{*}$ & 0.03 & $0.1^{*}$ & $0^{*}$ & 0 & $0.07^{*}$ \\
\hline March & $0.12^{\star *}$ & $0.07^{\star *}$ & $0.1^{*}$ & $0.1^{\star}$ & $0^{*}$ & $0.06^{* *}$ & $0.07^{*}$ \\
\hline April & $0.12^{\star *}$ & 0 & 0 & $0.1^{\star}$ & $0^{*}$ & 0 & -0.07 \\
\hline May & $0.12^{\star *}$ & 0 & -0.03 & 0 & $0^{*}$ & 0 & -0.07 \\
\hline June & -0.06 & 0 & -0.03 & 0 & $0^{*}$ & 0 & -0.07 \\
\hline July & -0.24 & 0 & -0.06 & 0 & -0.12 & -0.06 & -0.07 \\
\hline August & -0.18 & -0.07 & -0.13 & -0.1 & -0.12 & -0.12 & -0.13 \\
\hline September & 0.06 & $0.07^{* *}$ & $0.06^{* *}$ & $0.1^{\star}$ & $0^{*}$ & $0.06^{* *}$ & $0^{* *}$ \\
\hline October & -0.06 & $0.15^{*}$ & 0 & 0 & -0.12 & -0.06 & $0.07^{*}$ \\
\hline November & -0.12 & 0 & -0.03 & 0 & -0.12 & -0.06 & -0.07 \\
\hline December & -0.06 & -0.07 & -0.03 & 0 & -0.12 & -0.06 & -0.07 \\
\hline
\end{tabular}

In Table II, the highest $z$-values are indicated by the single asterisk and second highest $\mathrm{z}$-values indicated by the double asterisks. As can be noted, first three months of the year had the highest $\mathrm{z}$-values for all the variables tested. Furthermore, month of September also had high z-values.

A non-parametric Sign test was then used to distinguish significant birth months from the z-test table. For that we used the number of occurrences of the highest and second highest values for seven variables tested in each of the birth months. January and March had 7 out of 7 high $z$-values $(p<0.001)$ and September had 6 out of 7 high $z$-values $(p<0.01)$. 


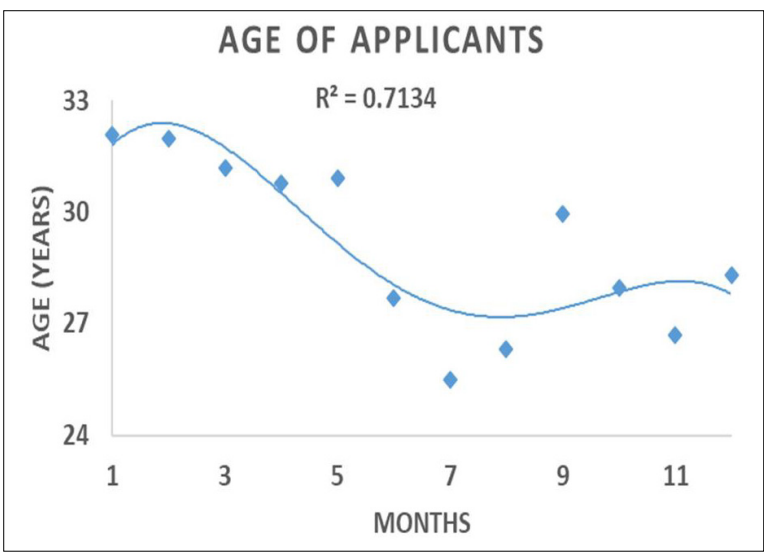

Figure 1. Age of the applicants and month of birth were significantly correlated $(R 2=0.7134 ; p<0.01)$ : As can be seen, the participants born in the first five months of the year were older when they applied to our obesity clinic compared with the persons born in the months from June to December.

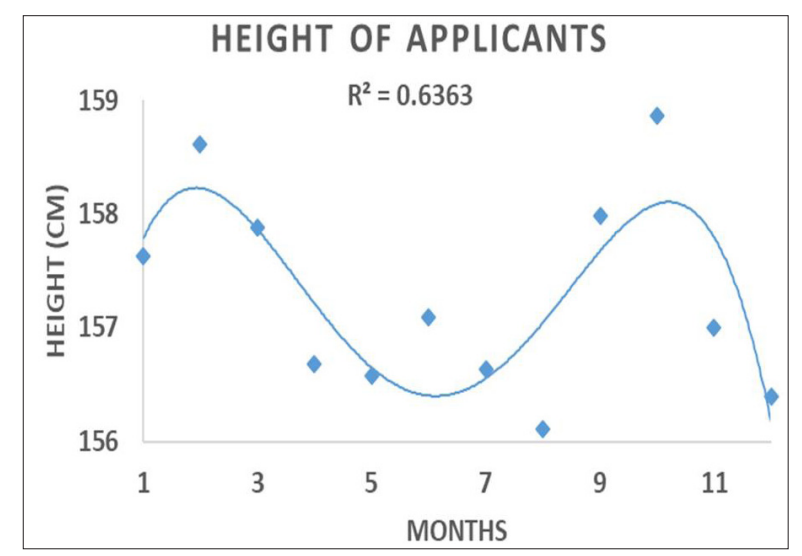

Figure 2. The height of the applicants had two peaks: One peak in February and the other peak in October. The trend again was significant: $R 2=0.6363(p<0.01)$

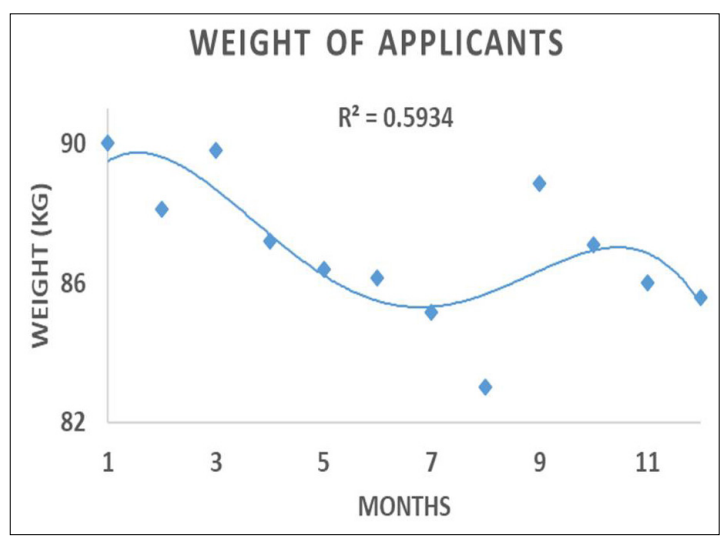

Figure 3. The weight of the applicants had one peak: One peak in the first three months of the year. The trend again was significant: $R 2=0.5934$ $(p<0.05)$

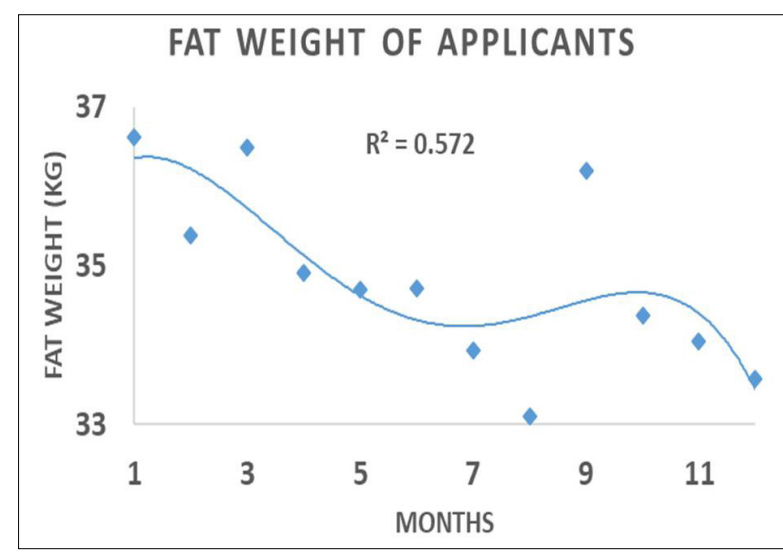

Figure 4. The fat weight of the applicants also had one peak: Very similar to the finding in the weight of the applicants, fat weight also had one peak and that was occurring in the first three months of the year. The trend again was significant: $R 2=0.572(p<0.05)$

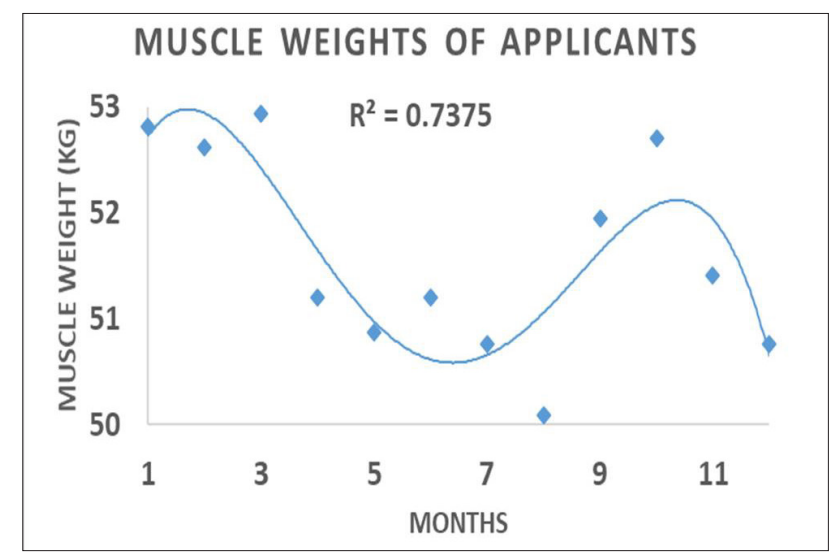

Figure 5. Muscle weight of the applicants had two peaks: One peak in the first three months of the year and the other peak in October. The trend again was significant: $R 2=0.7375(p<0.01)$. Similar to the Trendline curve for the height of the individuals.

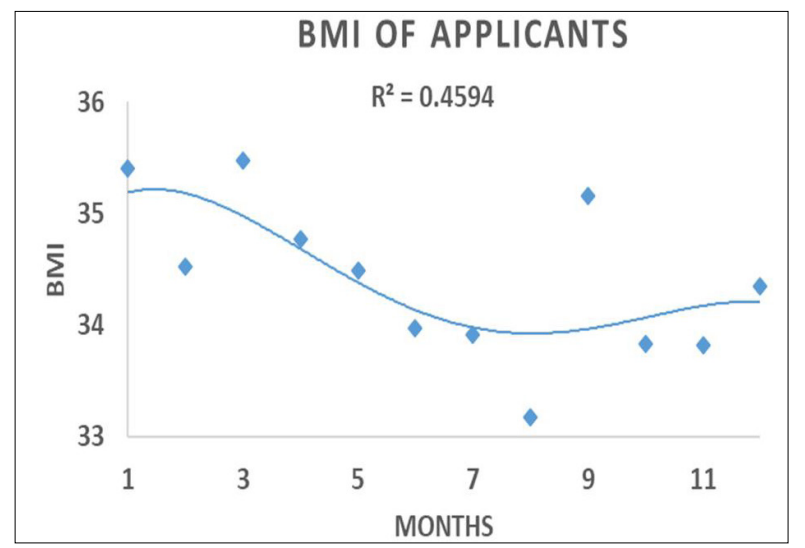

Figure 6. BMI of the applicants had a single peak: There was only one peak in the first three months of the year. The trend again was significant: $R 2=0.4594(p<0.05)$ 


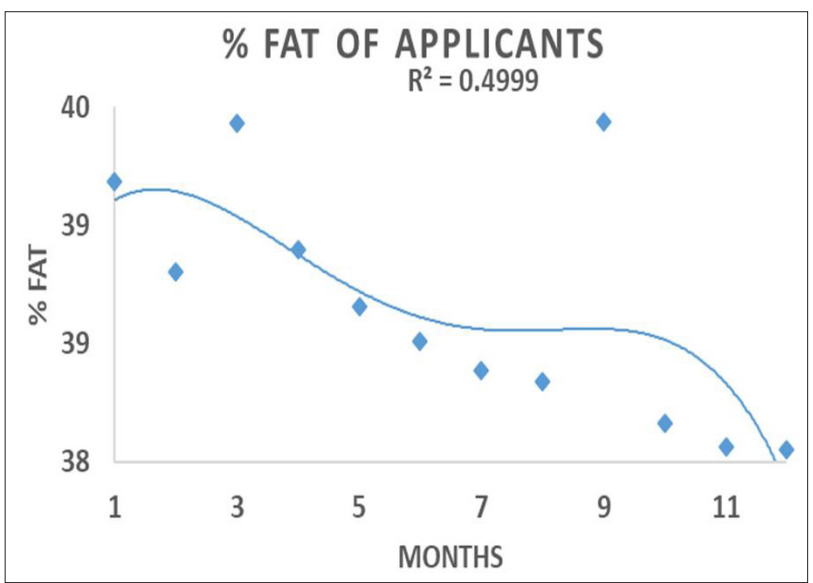

Figure 7. Percentage fat of the applicants had one peak: The peak appeared in the first three month of the year. The trend again was significant: $R 2=$ $0.4999(p<0.05)$

\section{DISCUSSION}

We have two original findings to report in this investigation: Firstly, we found that the age of the applicants was the highest in the applicants who were born in early months of the year and again this number has reduced in applicants who were born in later months of the year. Secondly, the subjects who were born in the early months of the year were taller, heavier and had more muscle and fat mass than the subjects born in other months of the year.

Older age applicants in early months of the year: This finding is difficult to explain since the age of applicants is not expected to vary with months of the year. However, the fact that birth years are utilized to calculate the age of individuals may introduce a slight error in the age calculations since at any time of the year the January born individuals should be "older" than others who are born in later months of the year. This calculation error strengthens our findings further as we have found that January born individual were older when they have applied to our clinic. The only explanation that we can think of for this unusual finding is the suggestion that self-awareness increases with age [12]. It has been reported by a group of researchers in Tanzania that obesity awareness increases with the age of individuals and older people become more self-aware than the younger individuals regarding body fat [12]. Therefore, it is not surprising that the older individuals are more aware about the consequence of being fat and hence may respond to our clinic to find a solution to their weight problem.

Taller, heavier, and more obese applicants are born in the early months of the year: Comparison of our findings with that of the previously reported height and obesity incidences vary very much. For example, a Chinese study showed that spring - and early summer-born adults had shorter legs, higher body mass index and wider waist circumference [7]. A Japanese study showed that spring born children were heavier and taller than winter born children, but the prevalence of obesity did not vary with the season of birth [8]. A Polish study found the opposite, i.e., children born in April to September were generally less heavy and shorter than those born in October to March [9]. A somewhat similar finding to the Polish study came from a South African study that showed that individuals born in February to July were weighed less (by 17\%) and shorter than those born in August to January [10]. A British study showed that in men, BMI and the prevalence of obesity (BMI $>$ or $=30 \mathrm{~kg} / \mathrm{m} 2)$ varied as a function of birth month and was greater among those born between January to June period than among those born in between July to December [13]. Benegas et al. have shown that male adults born in summer are $1.7 \mathrm{~cm}$ taller than their counterparts born in winter [3].

Our findings are similar but not the same as the Polish, British and South African studies where early month of the year was included in the birth month for more obese, heavier and taller adults. Therefore, there must be other factors underlying the current finding than simply to the seasonal temperature variation since during January, Turkey is in the middle of winter while South Africa is enjoying the height of summer. It is well-known that the environmental conditions (food, temperature and rainfall) in the Southern Hemisphere six months out of phase from those in the Northern Hemisphere. Consequently, the similarity of our findings to those from the Southern Hemisphere suggests a factor common for the entire globe, possibly related to the ellipsoid shape of the orbit of our planet around the sun [11]. It is well-known that the earth has an ellipsoid orbit around the sun and the sun is positioned in one of the two focal points of earth's ellipsoid orbit. The world comes closer to the sun in the Northern winter / Southern summer months and hence it is axiomatic that it would receive more energy and babies born in these months may be fed from food that are richer in nutrients compared with the babies born in later months of the year [10, 11]. Furthermore, it has been shown that the infant weight gain in the first week of life is related to overweight at age 2 [14]. Therefore, overweight babies born in the high energy months may be heavier when they reach adult ages [15].

\section{Conclusion}

We found that the month of birth was significantly related to obesity incidence. Individuals born in early months of the year were heavier, taller and more obese than individuals born in later months of the year. This information adds to the knowledge on the importance of the relationship between birth month and physical and health characteristics of individuals living in a country with extreme seasonal temperatures. This information can be useful in predicting the health and welfare status of individuals and their awareness on their conditions.

Limitations of study: The study examines only the obese people who applied to our clinic. It does not include nonobese individuals. Lack of simple statistical analysis may be the limiting factor of the study. 


\section{Acknowledgements}

We are grateful to the individuals who volunteered to take part in this study. We confirm that this paper is free of conflict of interest.

\section{Compliance with Ethical Standards}

Ethical Approval: The study protocol was approved by the Local Ethics Committee.

Financial Support: The author has no relevant financial information to disclose.

Conflict of Interest: The author has no potential conflicts to disclose.

\section{REFERENCES}

[1] Barker DJ. The developmental origins of adult disease. J Am Coll Nut 2004;23: 588-95. doi: 10.1080/07315.724.2004.1071 9428.

[2] Kloner RA, Poole WK, Perrit LR. When throughout the year is coronary death most likely to occur? A 12-year population - based analysis of more than 220000 cases. Circulation 1999;100:1630-4. doi: 10.1161/01.cir.100.15.1630.

[3] Banegas JR, Rodríguez-Artalejo F, Graciani A, de la Cruz JJ, Gutiérrez-Fisac JL. Month of birth and height of Spanish middle-aged men. Annals of Human Biology 2001;28:15-20. doi.org/10.1080/030.144.60150201841

[4] Day FR, Forouhi NG, Ong KK, Perry JR. Season of birth is associated with birth weight, pubertal timing, adult body size and educational attainment: A UK Biobank study. Heliyon. 2015;12:1-16. doi: 10.1016/j.heliyon.2015.e00031.

[5] Reffelmann T, Ittermann T, Empen K, Dörr M, Felix SB. Is cardiovascular mortality related to the season of birth? evidence from more than 6 million cardiovascular deaths between 1992 and 2007. J Am Coll Cardiol 2011;57:887-8. doi: 10.1016/j.jacc.2010.10.021.

[6] Banegas JR, Rodríguez-Artalejo F, de la Cruz JJ, Graciani A, Villar F, del Rey-Calero J. Adult men born in spring have lower blood pressure. J Hypertens 2000;18:1763-6. doi: 10.1097/00004.872.200018120-00009.

[7] Lv J, Yu C, Guo Y, et al. The associations of month of birth with body mass index, waist circumference, and leg length: findings from the China Kadoorie Biobank of 0.5 million adults. J Epidemiol 2015;25:221-30. doi: 10.2188/jea.JE20140154.

[8] Tanaka H, Sei M, Binh TQ, Munakata, Yuasa K, Nakahori Y. Correlation of month and season of birth with height, weight and degree of obesity of rural Japanese children. J Med Invest 2007;54:133-9. doi: 10.2152/jmi.54.133.

[9] Kościński K, Krenz-Niedbała M, Kozłowska-Rajewicz A.Month-of-birth effect on height and weight in Polish rural children. Am J Hum Biol 2004;16:31-42. doi: 10.1002/ ajhb.10232.

[10] Henneberg M, Louw GJ. Height and weight differences among South African Urban schoolchildren born in various months of the year. Am J Hum Biol 1990;2:227-33. doi: 10.1002/ ajhb.131.002.0304.

[11] Henneberg M, Louw GJ. Further studies on the month-ofbirth effect on body size: rural schoolchildren and an animal model. Am J Phys Anthropol 1993;91:235-244. doi: 10.1002/ ajpa.133.091.0209.

[12] Nyaruhucha CN, Achen JH, Msuya JM, Shayo NB, Kulwa KB. Prevalence and awareness of obesity among people of different age groups in educa-tional institutions in Morogoro,Tanzania. East Afr Med J 2003;80:68-72. doi: 10.4314/eamj.v80i2.8648.

[13] Phillips DI, Young JB. Birth weight, climate at birth and the risk of obesity in adult life. Int J Obes Rela Metab Disord 2000;24:281-7. doi: 10.1038/sj.ijo.0801125.

[14] Feldman-Winter L, Burnham L, Grossman X, Matlak S, Chen $\mathrm{N}$, Merewood A. Weight gain in the first week of life predicts overweight at 2 years: A prospective cohort study. Matern Child Nutr 2018;14:e12472. doi: 10.1111/mcn.12472.

[15] Phillips D, Young J. Birth weight, climate at birth and the risk of obesity in adult life. Int J Obes 2000;24:281-7. https://doi. org/10.1038/sj.ijo.0801125 